\title{
Carotid Vascular Strain Predicts Cardiovascular Events in Patients with Hypertension
}

\author{
Wei-Chuan Tsai ${ }^{1}$, Wen-Huang Lee ${ }^{1}$, Huey-Ru Tsai ${ }^{1}$, and Mu-Shiang Huang ${ }^{1}$ \\ ${ }^{1}$ National Cheng Kung University Medical Center
}

June 1, 2021

\begin{abstract}
Background: We aim to investigate prognostic effects of carotid strain (CS) and strain rate (CSR) in hypertension. Methods: We prospectively recruited 120 patients being treated for hypertension $(65.8 \pm 11.8$ years, $58 \%$ male $)$ in this observational study. Peak circumferential CS and peak CSR after ejection were identified using two-dimensional speckle tracking ultrasound. Major cardiovascular events were any admission for stroke, acute coronary syndrome, and heart failure. Results: After a mean follow-up period of $63.6 \pm 14.5$ months, $14(12 \%)$ patients had cardiovascular events. Age $(75.3 \pm 9.2$ vs. $64.6 \pm 11.6$ years; $\mathrm{p}=$ $0.001)$, systolic blood pressure $(131.8 \pm 15.5$ vs. $143.1 \pm 16.6 \mathrm{mmHg} ; \mathrm{p}=0.021)$, diastolic blood pressure $(74.6 \pm 11.4 \mathrm{vs} .82 .1$ $\pm 12.2 \mathrm{mmHg} ; \mathrm{p}=0.039)$, use of diuretics (71 vs. $92 \% ; \mathrm{p}=0.014)$, carotid CS $(2.17 \pm 1.02$ vs. $3.28 \pm 1.14 \%$; $=0.001)$, and CSR $(0.28 \pm 0.17$ vs. $0.51 \pm 0.181 / \mathrm{s} ; \mathrm{p}<0.001)$ were significantly different between the patients who did and did not reach the end-points. Multivariate Cox regression analysis controlling for age, systolic blood pressure, diastolic blood pressure, and use of diuretics showed that CS (HR 0.425, 95\% CI 0.223-0.811, p = 0.009) and CSR (HR 0.001, 95\% CI 0.000-0.072, p = 0.001) were independent predictors for cardiovascular events. Conclusion: In conclusions, decreased CS and CSR were associated with cardiovascular events in hypertension.
\end{abstract}

\section{Hosted file}

Px of Carotid strain(echocardiography) c table.doc available at https://authorea.com/ users/417358/articles/524490-carotid-vascular-strain-predicts-cardiovascular-eventsin-patients-with-hypertension 


\section{A.}

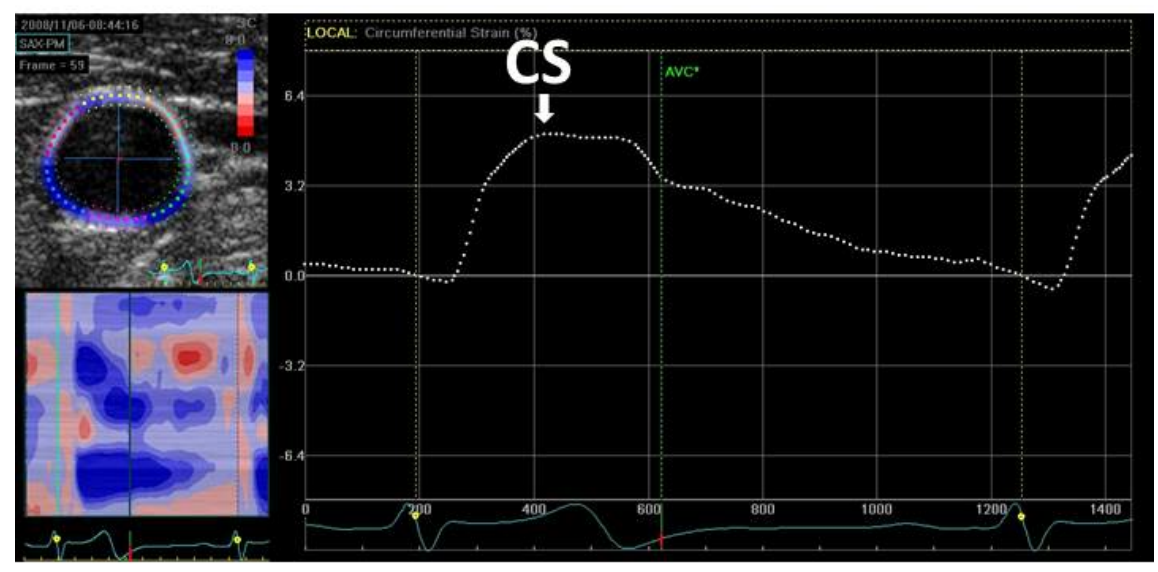

B.

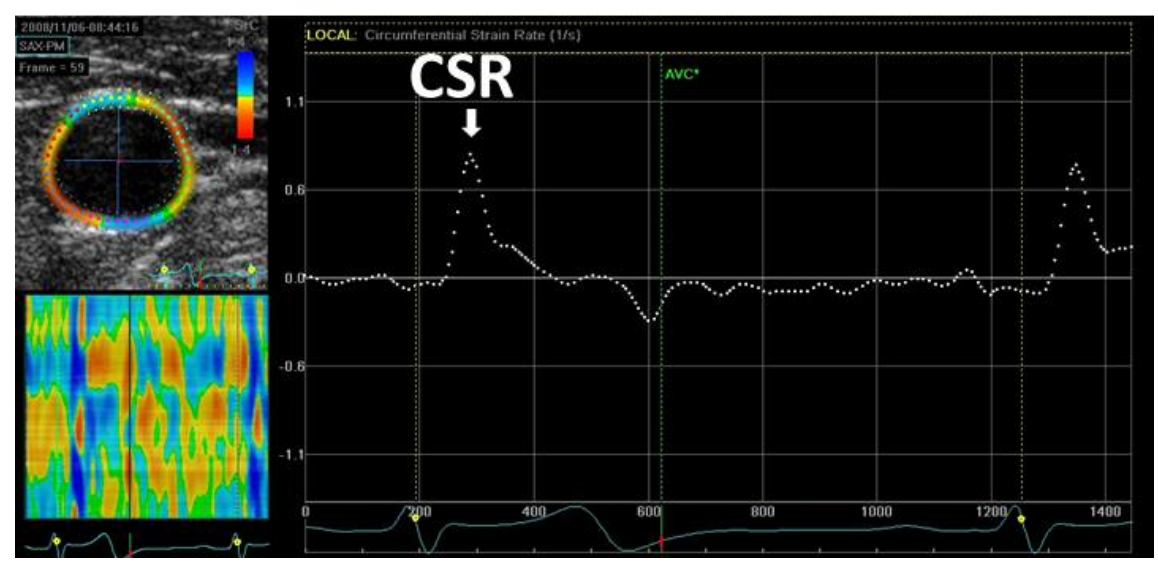



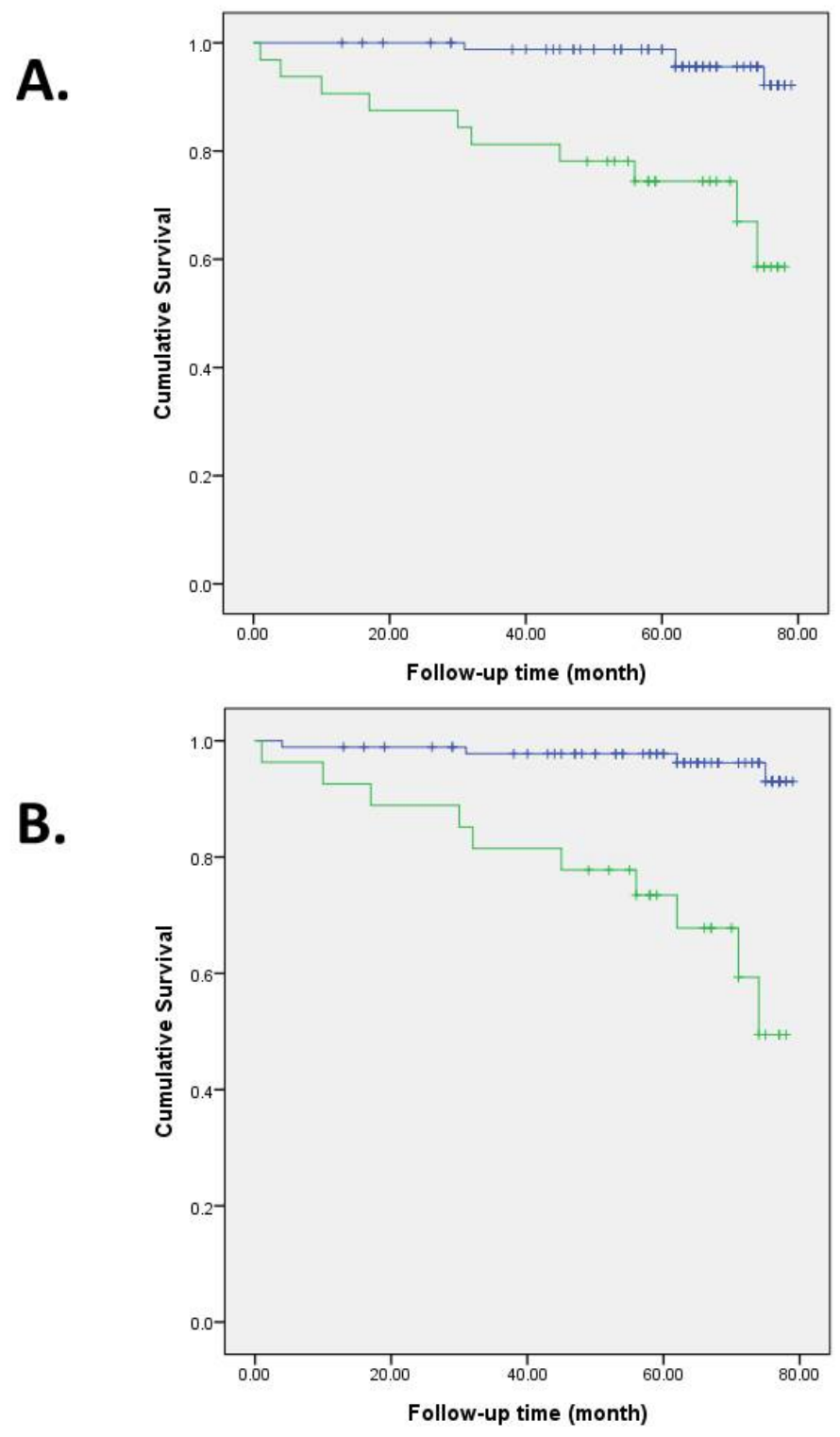